\title{
ACTA BORUSSICA
}

Neue Folge

2. Reihe: Preussen als Kulturstaat

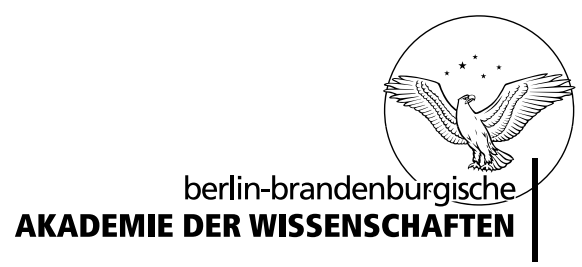




\title{
ACTA BORUSSICA \\ Neue Folge \\ 2. Reihe: Preussen als Kulturstaat
}

Herausgegeben von der

Berlin-Brandenburgischen Akademie der Wissenschaften

(vormals Preußische Akademie der Wissenschaften)

\author{
unter der Leitung \\ von \\ Wolfgang Neugebauer
}




\title{
Abteilung II \\ Der preußische Kulturstaat in der politischen und sozialen Wirklichkeit
}

\author{
Band 6 \\ Preußens Zensurpraxis von 1819 bis 1848 \\ in Quellen
}

Bärbel Holtz

1. Halbband

De Gruyter Akademie Forschung 
Dieser Band wurde durch die Gemeinsame Wissenschaftskonferenz im Akademienprogramm mit Mitteln des Bundes (Bundesministerium für Bildung und Forschung) und des Landes Berlin (Senatsverwaltung für Wirtschaft, Technologie und Forschung) gefördert.

ISBN 978-3-11-040913-0

e-ISBN (PDF) 978-3-11-040927-7

e-ISBN (EPUB) 978-3-11-040932-1

Library of Congress Cataloging-in-Publication Data

A CIP catalog record for this book has been applied for at the Library of Congress.

Bibliografische Information der Deutschen Nationalbibliothek

Die Deutsche Nationalbibliothek verzeichnet diese Publikation in der Deutschen Nationalbibliografie; detaillierte bibliografische Daten sind im Internet über http://dnb.dnb.de abrufbar.

(C) 2015 Walter de Gruyter GmbH, Berlin/Boston

Umschlagentwurf: Ingo Scheffler, Berlin

Lektorat: Anne Wendt, Berlin

Satz: work:at:Book, Martin Eberhardt, Berlin

Druck und Bindung: Hubert \& Co. GmbH \& Co. KG, Göttingen

Gedruckt auf säurefreiem Papier

Printed in Germany

www.degruyter.com 